\title{
Staphylococcus aureus Enterotoxin B Down-Regulates the Expression of Transforming Growth Factor-Beta (TGF- $\beta$ ) Signaling Transducers in Human Glioblastoma
}

\author{
Abolfazl Akbari,, Zohreh Farahnejad, ${ }^{2}$ Javad Akhtari,, Mahdi Abastabar,, Gholam Reza Mobini, ${ }^{5}$ and \\ Amir Seied Ali Mehbod ${ }^{2, *}$ \\ ${ }^{1}$ Colorectal Research Center, Iran University of Medical Sciences, Tehran, IR Iran \\ ${ }^{2}$ Department of Medical Mycology, AJA University of Medical Sciences, Tehran, IR Iran \\ ${ }^{3}$ Immunogenetic Research Center, Faculty of Medicine, Mazandaran University of Medical Sciences, Sari, IR Iran \\ ${ }^{4}$ Department of Medical Mycology and Parasitology, Invasive Fungi Research Center, School of Medicine, Mazandaran University of Medical Sciences, Sari, IR Iran \\ ${ }^{5}$ Medical Plants Research Center, Shahrekord University of Medical Sciences, Shahrekord, IR Iran \\ "Corresponding author: Amir Seied Ali Mehbod, Department of Medical Mycology, AJA University of Medical Sciences, Tehran, IR Iran. Tel: +98-2188028350, Fax: +98-2188028350, \\ E-mail: dr.mehbod51@yahoo.com
}

Received 2015 February 01; Revised 2015 August 08; Accepted 2015 October 19.

\begin{abstract}
Background: It has been revealed that Staphylococcus aureus enterotoxin B (SEB) may feature anti-cancer and anti-metastatic advantages due to its ability to modify cell immunity processes and signaling pathways. Glioblastoma is one of the most aggressive human cancers; it has a high mortality nature, which makes it an attractive area for the development of novel therapies.

Objectives: We examined whether the SEB could exert its growth inhibitory effects on glioblastoma cells partially through the manipulation of a key tumor growth factor termed transforming growth factor-beta (TGF- $\beta$ ).

Materials and Methods: A human primary glioblastoma cell line, U87, was treated with different concentrations of SEB. The cell quantity was measured by the MTT assay at different exposure times. For molecular assessments, total ribonucleic acid (RNA) was extracted from either non-treated or SEB-treated cells. Subsequently, the gene expression of TGF- $\beta$ transducers, smad2/3, at the messenger RNA (mRNA) level, was analyzed via a quantitative real-time polymerase chain reaction (qPCR) using the SYBR Green method. Significant differences between cell viability and gene expression levels were determined (Prism 5.0 software) using one-way analyses of variance (ANOVA) test.

Results: We reported that SEB could effectively down-regulate $s m a d 2 / 3$ expression in glioblastoma cells at concentrations as quantity as $1 \mu \mathrm{g} / \mathrm{mL}$ and $2 \mu \mathrm{g} / \mathrm{mL}(\mathrm{P}<0.05$ and $\mathrm{P}<0.01$, respectively). The SEB concentrations effective at regulating smad2/3 expression were correlated with those used to inhibit the proliferation of glioblastoma cells. Our results also showed that SEB was able to decrease smad2/3 expression at the mRNA level in a concentration- and time-dependent manner.

Conclusions: We suggested that SEB could represent an agent that can significantly decrease smad2/3 expression in glioblastoma cells, leading to moderate TGF- $\beta$ growth signaling and the reduction of tumor cell proliferation.
\end{abstract}

Keywords: Cell Signaling Transducers, Glioblastoma, Transforming Growth Factor- $\beta$ (TGF- $\beta$ ), Staphylococcus aureus enterotoxin B

\section{Background}

Glioblastoma, a malignant type of brain cancer, is one of the most aggressive human cancers in adults. This cancer is usually considered to have a high degree of morbidity and mortality $(1,2)$. Despite the progress that has been made in understanding the molecular mechanisms involved in the genesis and progression of glioblastoma, prognosis and treatment are refractory to radiotherapy and chemotherapy. These characteristics make this tumor type an excellent area for cancer research and therapeutic approaches (2). On the other hand, it is well known that the aberration of the growth factors signaling pathways could play an important role in tumor initiation, progression and metastasis in glioblastoma $(3,4)$. Transform- ing growth factor beta (TGF- $\beta$ ) has been identified as a key growth factor that triggers various biological processes, such as proliferation, differentiation and programmed cell death. Studies have shown that cell signaling at the late stage of some cancers promote tumor development, progression and metastasis. Dysregulation of this pathway results in various cancers, including glioblastoma (4), colon, breast and prostate cancer $(5,6)$.

The TGF- $\beta$ signaling pathway is important in brain tumor cell homeostasis and supports glioblastoma cell proliferation and migration (4-6). This fact has prompted the development of anticancer strategies based on inhibition of this signaling pathway $(5,6)$. However, due to the complexity of the TGF- $\beta$ signaling pathway, it is crucial to un- 
derstand how TGF- $\beta$ inhibition affects tumor biology in order to assess and improve the therapeutic potential and clinical testing of anti-TGF- $\beta$ compounds. TGF- $\beta$ molecule binds to heterodimeric receptor complexes of transmembrane serine/threonine kinases called type I and type II receptors (TG $\beta$ RI and TG $\beta$ RII). Cell signaling is triggered through the interaction of the TGF- $\beta$ and the following TG $\beta$ RII to activate TG $\beta$ RI. Activated TG $\beta$ RI then results in the recruitment and phosphorylation of a family of transcription factors or signal transducers termed smad factors.

A complex of phosphorylated smad2 and smad3 components associates with smad4 and translocates to the nucleus, where the transcription of downstream target genes is activated $(7,8)$. The regulation of signaling components' expression and function should include mechanisms that allow for a diversity of events depending on cell and tissue contexts $(8,9)$. Several reports imply that the targeting of a TGF- $\beta$ signaling pathway at the late stage of carcinogenesis could be a helpful tool for the treatment of human cancers, such as glioblastoma, colorectal and breast cancer. Thereby, repressing the TGF- $\beta$ signal transducer expression could provide a rational therapeutic strategy for the treatment of these cancers (8-10). For hundreds of years, it has been recorded that certain infectious diseases could exert a beneficial therapeutic effect upon some malignancies $(11,12)$.

Using bacteria and their components in cancer therapy has been executed in different fields, including utilizing, as a vector for gene therapy, carriers of tumoricidal agents and bacterial toxins as a tumor repressor via binding to tumor-surface antigens. One unique bacterial factor that would suggest a protective role in carcinogenesis or cause the remission of a cancer is a toxin (13-15). Evidence is growing that certain types of bacterial toxins have emerged as being promising in the prevention or cure of cancers. This fact inspired the development of the earliest toxin-based cancer therapies (11-13). Some bacteria are well known for their ability to secrete enterotoxins changing cellular signaling processes that control proliferation, apoptosis and differentiation in carcinogenesis (16-19).

Regarding the basic function of bacterial enterotoxins in tumor regression, it is rational to hypothesize that anticancer properties may partially be related to their alteration of the cell signaling genes involved in cancer development and progression. However, modulation of a distinct signaling pathway that would explain the possible inhibitory action of Staphylococcal enterotoxins on cancers, in particular glioblastoma, has not been elucidated. Staphylococcal enterotoxins are a family of structurally related proteins produced by Staphylococcus aureus, termed superantigens. These proteins bind to major histocom- patibility complex (MHC)-II molecules on cells and induce $\mathrm{T}$ lymphocytes clonally $(20,21)$. It has been revealed that Staphylococcus aureus enterotoxin B (SEB) may feature anticancer and anti-metastatic advantages due to their ability to modify cell immunity processes as well as cancer cell signaling pathways (20). These attractive characteristics stimulated us to research whether this enterotoxin may reduce the proliferation of glioblastoma cells. Because this bacterial enterotoxin has been previously experienced for cancer treatment (20-23), we hypothesized that the anti-cancer properties of the toxin could partially stem from changes in growth signaling pathways.

\section{Objectives}

Our aim was to investigate the human glioblastoma growth inhibitory effect of SEB through the manipulation of TGF- $\beta$ signaling pathway transducers, $\operatorname{smad} 2 / 3$, in vitro. The study was designed to provide insight into the molecular mechanism of SEB in human glioblastoma cell signaling pathways, emphasizing the potential novel idea in toxin-based cancer therapy.

\section{Materials and Methods}

\subsection{Cell Culture}

A human primary glioblastoma cell line with a pathologic differentiation grade of original tumors II, U87, was selected for examining the effect of SEB on TGF- $\beta$ signaling transducers. The cell line was obtained from the national cell bank of Iran (NCBI) affiliated with Pasteur Institute(Tehran, Iran) and was grown in an RPMI-1640 medium (Gibco; Germany) containing $25 \mathrm{mM}$ D-glucose, $4 \mathrm{mM} \mathrm{L}-$ glutamine and $1 \mathrm{mM}$ sodium pyruvate and supplemented with $5 \%(\mathrm{v} / \mathrm{v})$ heat-inactivated fetal bovine serum (FBS) (Gibco; Germany), 2 mM glutamax (Gibco; Germany), 100 $\mathrm{U} / \mathrm{mL}$ penicillin, $100 \mu \mathrm{g} / \mathrm{mL}$ streptomycin and $250 \mathrm{ng} / \mathrm{mL}$ amphoterycin (Gibco; Germany) in a culture flask that was $25 \mathrm{~cm}^{2}$ (SPL Life Sciences; South Korea). The cells were kept at $37^{\circ} \mathrm{C}$ in a humidified $95 \%$ atmosphere in a $5 \% \mathrm{CO}_{2}$ atmosphere incubator designated as the culture in a steadystate condition. The cell viability was assessed using a trypan blue exclusion test and was routinely found in all flasks containing more than $95 \%$ viable cells.

\subsection{Staphylococcus aureus Enterotoxin B (SEB) Preparation}

Staphylococcus aureus enterotoxin B was purchased from Sigma Aldrich (Belgium) and was dissolved in distilled water according to the manufacturer's instruction. The enterotoxin was prepared as stock solutions of 20 $\mu \mathrm{g} / \mathrm{mL}$ and kept at $-20^{\circ} \mathrm{C}$ until use. 


\subsection{Methyl Thiazolyltetrazolium (MTT) Assay}

To quantify cell proliferation, the in vitro growth inhibitory effect of SEB was measured using the MTT assay (Roche Applied Science; Germany). Briefly, monolayer cultures were trypsinized in the exponential growth phase, and viable cell counts were assessed using trypan blue exclusion. Then, cells were seeded in 96 well flat-bottom micro titration plates (SPL Life Sciences; South Korea) at a density of 105 cells/well (200 $\mu$ L media/well). After 24 hours, once the cells reached $\sim 85 \%$ confluence, they were treated with different concentrations of SEB $(0.5 \mu \mathrm{g} / \mathrm{mL}, 1 \mu \mathrm{g} / \mathrm{mL}$ and $2 \mu \mathrm{g} / \mathrm{mL}$ ). Following 24 hours drug exposure, for the recovery period, the cells were washed two times with fresh and free-FBS medium, and the culture continued (Figure 1). Subsequently, a fresh medium containing FBS was replaced for the removal of unbound SEB. In all in vitro experiments, control cells were incubated with distilled water (DW) alone (with a final volume of $5 \mu \mathrm{L}$ ). The complete medium was replaced with $100 \mu$ L MTT after 24,48 , and 72 hours incubation periods. The cells were incubated for 3 hours at $37^{\circ} \mathrm{C}$, and then $100 \mu \mathrm{L}$ dymethyl sulfoxide (DMSO) was added to each well. Finally, the optical density(OD) was measured at a wavelength of $570 \mathrm{~nm}$ with background subtraction at $630 \mathrm{~nm}$ using a spectrophotometric micro plate reader (BioTekElx. 808). The cell viability was calculated using the following formula:

Cell Viability $(\%)=\frac{O D_{\text {toxin exposure }}}{\mathrm{OD}_{\text {control }}} \times 100$

\subsection{Total Ribonucleic Acid (RNA) Extraction From Cells}

The cultured U87 cells, at the mentioned time points either before or after treatment with SEB, were subjected to total RNA extraction. Total cellular RNA was extracted using trizol reagent (Invitrogen; Germany) according to the manufacturer's instructions. Extracted total RNA was stored at $-80^{\circ} \mathrm{C}$ until use.

3.5. Gene Expression Analysis by Reverse-Transcription (RT) Real-Time Polymerase Chain Reaction (PCR)

smad2/3 gene expression at the mRNA level was analyzed via SYBR Green quantitative real-time polymerase chain reactions (qPCR) using the specific forward and reverse primers for the genes (Table 1). The GAPDH gene was used as an endogenous (internal) control, and the data were normalized to the expression level of this housekeeping gene. Our protocol included two steps: reverse transcription (RT) and real-time PCR. Briefly, RNA was transcripted to complementary deoxyribonucleic acid (cDNA) using the oligodT procedure. Briefly, the cDNA was synthesized using total RNA and specific primers in a reverse transcription reaction. This reaction was performed in a volume of $10 \mu \mathrm{L}$ containing $1 \mu \mathrm{L}$ total RNA, $1 \mu \mathrm{L}$ of $0.5 \mathrm{mM}$ oligodT RT primer, $1 \mu \mathrm{L}$ of $10 \mathrm{mM} \mathrm{dNTP}, 1 \mu \mathrm{L}$ RT enzyme and $6 \mu \mathrm{L}$ reaction buffer.

The reaction was incubated at $42^{\circ} \mathrm{C}$ for 60 minutes and then terminated by heating at $85^{\circ} \mathrm{C}$ for 5 minutes. Subsequently, diluted cDNAs were amplified in a $20 \mu \mathrm{L}$ reaction containing SYBER Green master mix, forward and reverse Sma2/3 specific primers (each $1 \mu \mathrm{L}$ ) and diethylpyrocarbonate (DEPC)-treated distilled water by 35 cycles of PCR amplification under the following conditions: denaturing at $95^{\circ} \mathrm{C}$ for 1 minute, annealing at $56^{\circ} \mathrm{C}$ for 1 minute, and extension at $72^{\circ} \mathrm{C}$ for 1 minute. Real-time PCR was carried out on a Bio Rad CFX96 Real-Time PCR system. All of the reactions were performed in triplicate. The specificity of primers was verified by observing a single peak dissociation curve for each run. The threshold cycle (CT) was defined as the fractional cycle number at which the [U+FB02] uorescence passed the fixed threshold. CT values were converted into total copy numbers using a standard curve. The absence of contamination was verified using non-template controls. PCR products were also visualized by electrophoresis on a $2 \%$ agarose gel stained by gel red (Figure 2).

Table 1. The Specific Primer Sequences Used in This Study

\begin{tabular}{ccc}
\hline Target Genes Primers & Sequences $\left(\mathbf{5}^{\prime} \rightarrow \mathbf{3}^{\prime}\right)$ & PCR Product Size, bp \\
\hline Smad2 & & 480 \\
\hline Forward & TCAAGCTTGAGTGTAAACCCI & \\
Reverse & TAGCGGCCGCGAAAGCTATGATTAACAG48GGG \\
\hline Smad3 & & 340 \\
\hline Forward & TCAAGCTTGAACACCAGTTCTACCTCCTG \\
\hline Reverse & TAGCGGCCGCGAAATGTCTCI & \\
\hline GAPDH & & 190 \\
\hline Forward & CGTTCCCAAAGTCCTCCTGTT \\
\hline Reverse & TTTTTTCCGCAGCCGCCTG \\
\hline
\end{tabular}

Real-time PCR data were analyzed using the $2^{-\Delta \Delta} \mathrm{ct}$ method via GraphPad Prism 5.0 software. A comparison of the cell viability and gene expression means was completed by analysis of variance (ANOVA) and Turkey's posttest. P values less than 0.05 were considered to indicate statistically significant differences between data sets. 

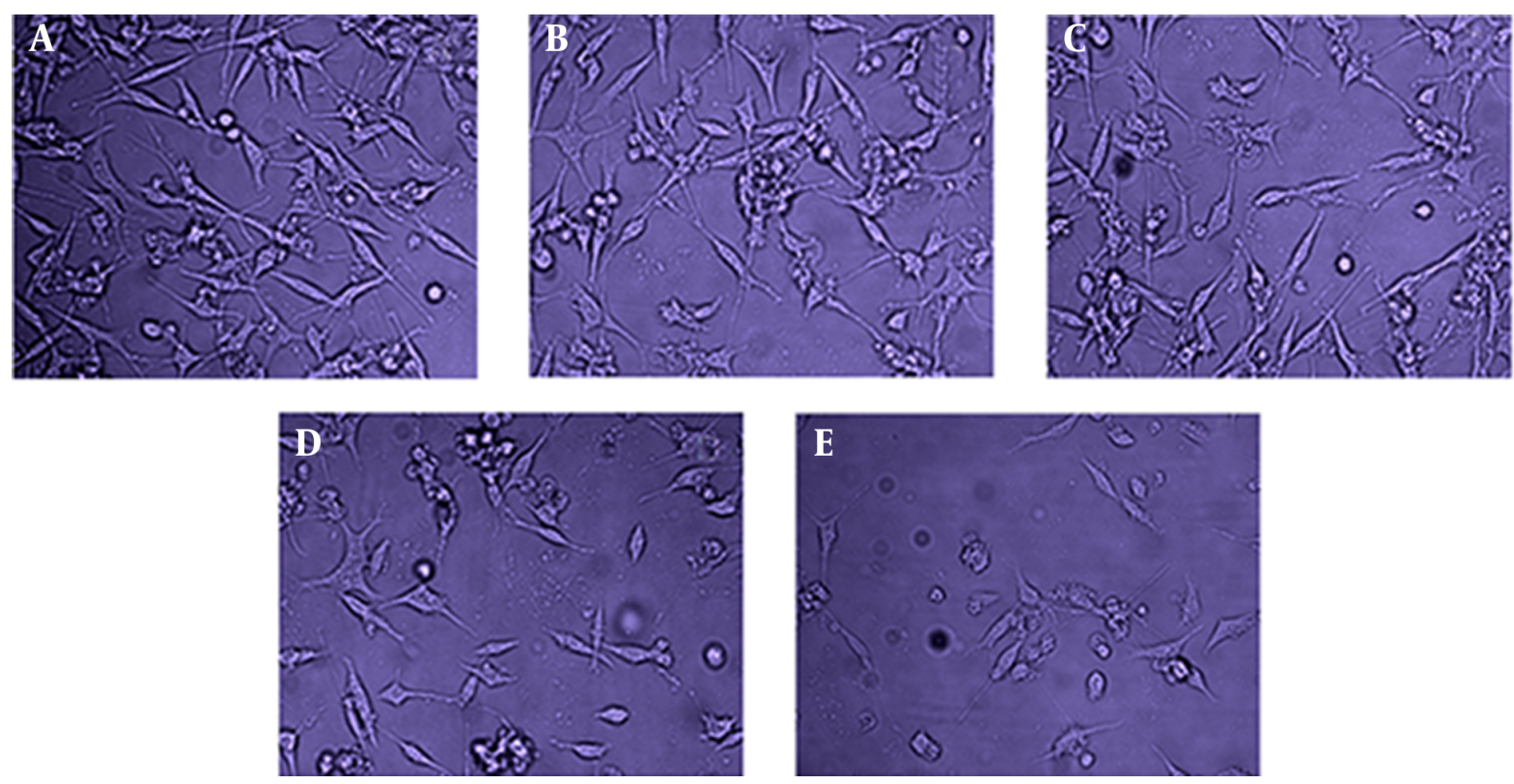

A U87 cell was cultured and treated with no (A); with distilled water as a control (B); with $0.5 \mu \mathrm{g} / \mathrm{mL}(\mathrm{C}) ; 1 \mu \mathrm{g} / \mathrm{mL}(\mathrm{D})$; and $2 \mu \mathrm{g} / \mathrm{mL}$ (E) concentrations of SEB. The cells were cultured as a monolayer in microtitration plates and evaluated microscopically after 48 hours of exposure.

\section{Figure 2. Gel Electrophoresis of PCR Products}

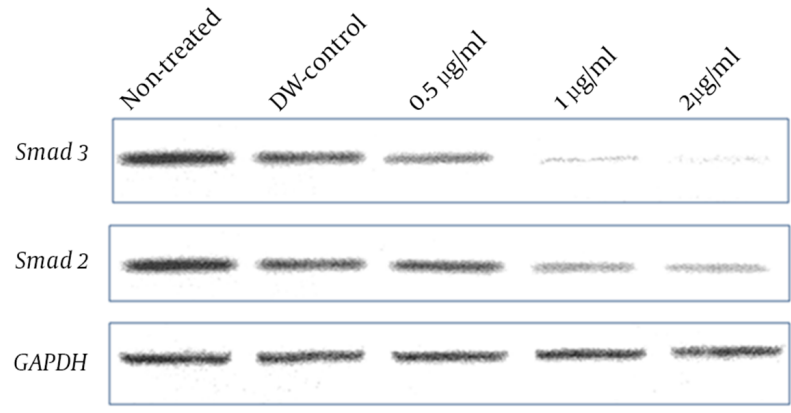

Smad 2/3 genes and the GAPDH housekeeping gene (as an internal control) PCR product were subjected to electrophoresis on gel agarose $2 \%$ stained with gel red.

\section{Results}

4.1. SEB Can Reduce the Proliferation of Human Primary Glioblastoma Cell Line U87

In order to examine the anti-proliferative activities of SEB, the growth inhibitory effect was evaluated by MMT assay in different concentrations and times. Our data showed that SEB could significantly decrease U87 cell viability after 48 hours in concentrations of 1 and $2 \mu \mathrm{g} / \mathrm{mL}(\mathrm{P}<$ $0.05, \mathrm{P}<0.01$, respectively). We concluded that SEB exerts its growth inhibitory effects in a concentration and timedependant manner. On the whole, the findings revealed that SEB was the effective inhibitor of human glioblastoma cell proliferation (Figure 3).

4.2. SEB Could Down-Regulate smad2/3 Expression in U87 Cell Line

The expression level of TGF- $\beta$ signal transducers, smad2/3, was evaluated by real-time PCR. Our results showed that SEB at concentrations of $1 \mu \mathrm{g} / \mathrm{mL}$ and $2 \mu \mathrm{g} / \mathrm{mL}$ could reduce smad2/3 expression in the human glioblastoma U87 cell line. SEB could significantly reduce the expression level of smad2 with a concentration of $2 \mu \mathrm{g} / \mathrm{mL}$ in 72 hours $(\mathrm{P}<0.01)$. However, the expression level of smad3 was significantly reduced by SEB treatment either at concentrations of $2 \mu \mathrm{g} / \mathrm{mL}$ in 48 hours $(\mathrm{P}<0.01)$ or 1 $\mu \mathrm{g} / \mathrm{mL}$ and $2 \mu \mathrm{g} / \mathrm{mL}$ in 72 hours $(\mathrm{P}<0.01$ and $\mathrm{P}<0.01$, respectively). The results revealed that SEB reduces smad2/3 expression in a dose- and time-dependent manner (Figure 4). Because SEB at high concentrations also exerts an inhibitory effect on U87 cells, it was presumed that this observable phenomenon could at least partially be a consequence of the down-regulated expression of TGF- $\beta$ signaling components.

Overall, we predicted that SEB, as a potent inhibitor of human glioblastoma cell proliferation, would regulate the 
Figure 3. Cell Viability of U87 After SEB Treatment

A

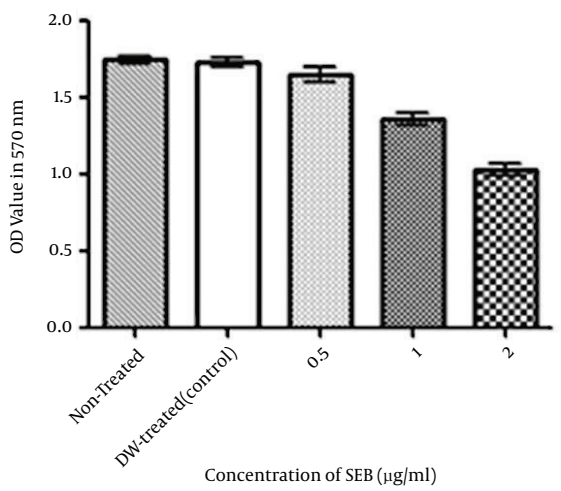

B

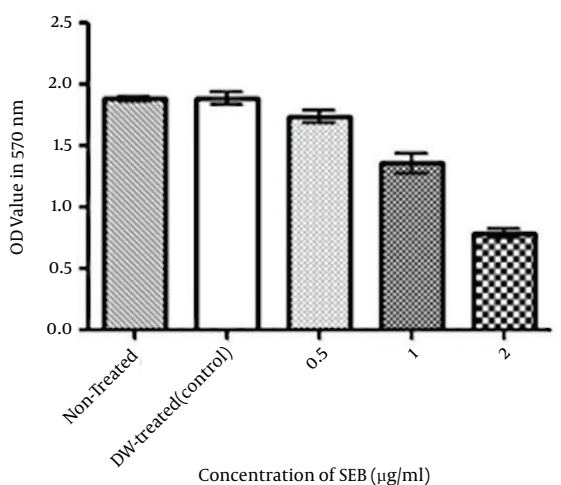

C

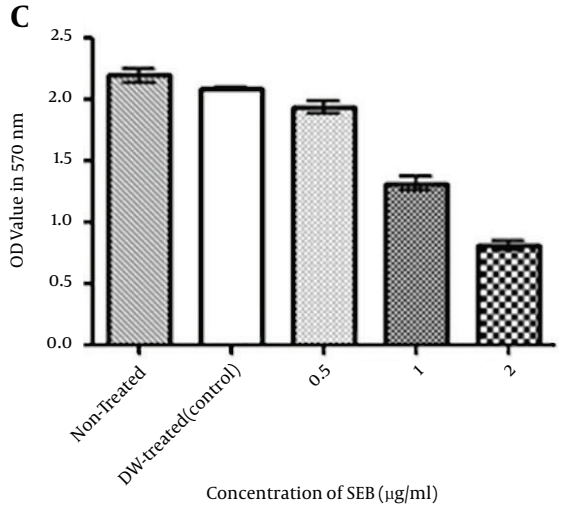

A, cell viability of U 87 after 24 hours of treatment; B, cell viability of U87 after 48 hours of treatment; C, cell viability of U87 after 72 hours of treatment. MTT assay results showed that SEB treatment at different times could significantly induce growth inhibitory effects on U87 cells in concentrations of $1 \mu \mathrm{g} / \mathrm{mL}$ and $2 \mu \mathrm{g} / \mathrm{mL}$.

gene expression of key transducers that control TGF- $\beta$ signaling in cancerous cells. Interestingly, the SEB concentrations effective at inhibiting the expression of $\operatorname{smad} 2 / 3$
Figure 4. Relative smad2/3 Gene Expression Normalized by Housekeeping Gene GAPDH
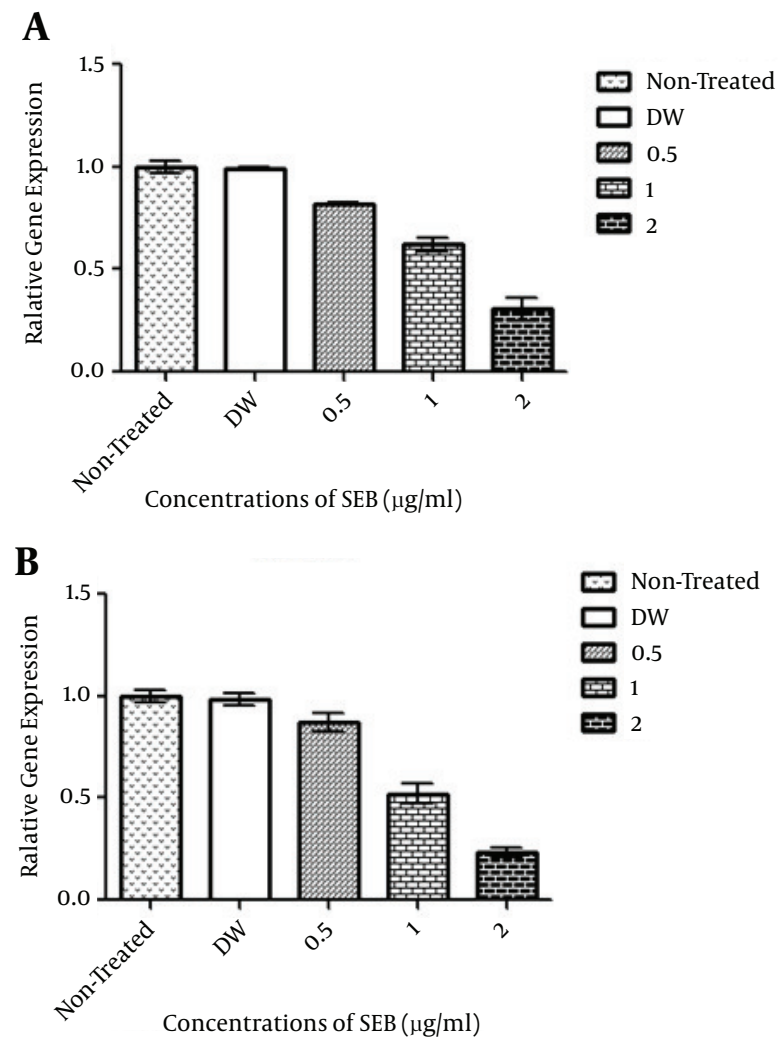

A, smad2; B, smad3.U87 cells after 48 hours of treatment with concentrations of 1 $\mu \mathrm{g} / \mathrm{mL}$ and $2 \mu \mathrm{g} / \mathrm{mL}$ of SEB showed a significant reduction in smad 2 and $\operatorname{smad} 2 / 33$ gene expression.

correlated with those used to decrease the proliferation of U87 cells. According to our data, it is thought the downregulation of $s m a d 2 / 3$ in the presence of SEB could precede the inhibitory effects of SEB on cell proliferation. However, this idea that SEB could cause a reduction in human glioblastoma proliferation through smad2/3 downregulation needs to be further evaluated.

\section{Discussion}

Nowadays, malignancies, including brain cancers, are considered an excellent area for research and therapy because of their high mortality rate (1-3). With regard to glioblastoma, it is well known that aberration in genes that encode transforming growth factor-beta (TGF- $\beta$ ) signaling components can contribute to carcinogenesis $(4,6)$. This signaling pathway can control many cellular functions, including cell proliferation, apoptosis and migration as well 
as tumor initiation, progression and metastasis $(6,7)$, making it as a suitable target in cancer therapy $(7,8)$. Bacterial toxins are a specific group of components that are now widely studied for their anticancer activities. A number of these toxins are in clinical development, which gives us hope for their pharmacological use as growth inhibitory agents in cancer treatment (12-14). These biomolecules can kill cells or alter cellular processes that control proliferation, apoptosis and differentiation. These attractive characteristics have stimulated research into whether these may be used as anticancer agents $(12,13,15)$.

In spite of reported in vitro and in vivo results, in order to make it the right therapeutic approach in cancer treatment, more investigations on cellular mechanism targeting by bacteria are required. In line with this, the cancerpromoting signaling pathways manipulated by bacterial toxins have been evaluated in various studies $(17,19)$. SEB belongs to super antigens family, whose functional activity is based on binding to both the $\beta$-chain of the $\mathrm{T}$ cell receptor (TcR) and the major histocompatibility complex (MHC) class II dimer (20). It has been suggested that SEB could exert anti-cancer and anti-metastatic effects due to their ability to modify cancer signaling pathways and their cell immunity $(21,22)$. Therefore, we hypothesized that the anti-cancer functions of the enterotoxin could be partially caused by changes in cancer signaling pathways.

According to one previous study on glioblastoma cell lines and normal brain tissues (22), it has been revealed that the U87 and U343 tumor cell lines are characterized by the increased expression of the major histocompatibility complex (MHC)-I and -II molecules. Because the existence of functionally active SEB-binding structures on U87 cells is suggested to mediate cellular modulations (22), we selected the U87 cell line as a promising target cell. We predicted that SEB, the potent inhibitor of human glioblastoma cell proliferation, could moderate the expression of key transducer genes that control TGF- $\beta$ signaling in cancer cells. This study was designed to provide insight into the molecular mechanisms of SEB in cell signaling pathways, emphasizing a potential novel idea in the cancer therapy of glioblastoma and other malignancies involving the TGF- $\beta$ signaling pathway. Through the treatment of U87 cells with SEB, we determined an inhibition of smad2/3 gene expression in U87 cells in a time- and concentration-dependent manner. The inhibitory action of SEB on smad2/3 expression took place at concentrations of either $1 \mu \mathrm{g} / \mathrm{mL}$ or $2 \mu \mathrm{g} / \mathrm{mL}(\mathrm{P}<0.05)$.

It was presumed that this observable phenomenon could at least partially be a consequence of the downregulated expression of TGF- $\beta$ signaling components. In addition, SEB was significantly more effective at reducing smad3 gene expression in comparison to smad2. We also revealed that after 48 hours of treatment at high concentrations $(1 \mu \mathrm{g} / \mathrm{mL}$ and $2 \mu \mathrm{g} / \mathrm{mL})$, SEB exerts an inhibitory effect on U87 cell proliferation $(\mathrm{P}<0.05$ and $\mathrm{P}<0.01$, respectively). The SEB concentrations effective in decreasing smad2/3 expression correlated with those used to inhibit the proliferation of U87 cells. According to our data, it is thought that the down-regulation of $\operatorname{smad} 2 / 3$ could precede the inhibitory effects of SEB on cell proliferation. However, further evaluations are needed to confirm this claim. In total, our findings are consistent with those from studies that showed SEB exerts anti-angiogenic effects (21, 22). In these studies, SEB was discovered to be effective in apoptosis and in harmonizing cancer cell proliferation. In line with our data, some researchers have shown that SEB could induce the Fas/Fas ligand-mediated cytolysis of target cells. They supposed that the Fas/Fas ligand could be a key mediator for SEB-mediated cell death (24).

In this regard, it should be noted that TGF- $\beta$ also activates other downstream signaling pathways, including Rho GTPases, the extra-cellular signaling-regulated kinases (ERK), C-Jun $\mathrm{NH}_{2}$-terminals kinase (JNK) and phosphatidylinositol-3;kinase (PI3K) (6-8). It is likely that these pathways are also affected by the enterotoxin. Therefore, this idea that SEB could represent a complete reduction in human glioblastoma proliferation only by smad2/3 down-regulation needs to be comprehensively examined. In addition, it has recently been reported that the anthrax toxin (a dangerous bacterial toxin secreted by Bacillus anthraces) inhibits the growth of ras-transformed cancerous cells by disturbing the mitogene-activated protein kinases (MAPKs) signaling pathway (23). Thus, it has been supposed that the agent could be used against cancer cells in which MAPKs are activated by oncogenic proteins.

These features ensure the selective damage of tumors yet at a very low dosage (24). Furthermore, other investigations imply that some bacterial toxins could be used in targeted-cancer therapy, and others synergistically promote the activity of the anticancer drugs $(25,26)$. Therefore, it is strongly proposed to complete additional supplementary studies to examine the synergistic activity of the enterotoxin with routine anticancer drugs. Our results suggested SEB could be used against cancer cells undergoing TGF- $\beta$ signaling dysregulation or likely over-activation by other oncogenic proteins. Although SEB is proposed to be an attractive bio-molecule for treating cancers, a major problem is its toxicity at the dose required for therapeutic efficacy. Moreover, insufficient experimental evidence exists to justify the conclusion that the SEB has therapeutic value in $\mathrm{TG} \beta \mathrm{RI} / \mathrm{II}$ positive cancer cells.

As a final point, the identification of the molecular mechanisms involved in bio-toxins' functions could pro- 
vide novel insight into immunotoxin-based cancer therapy. Further investigation and developments in these studies will add a new dimension to cancer treatment. The continued examination of these molecular aspects will bring research ever closer to the more effective therapies, such as the immunotoxin-based therapy of malignancies. Nonetheless, the successful translation of these approaches into scientific practice will depend on the outcome of intended clinical trials.

\section{Footnotes}

Authors' Contribution: Zohreh Farahnejad, Amir Seied Ali Mehbod and Abolfazl Akbari contributed to the study design. Abolfazl Akbari and Javad Akhtari contributed to the supervision of sections of the study. Abolfazl Akbari, Mahdi Abastabar and Gholam Reza Mobini assisted in the cell culture study and provided scientific advice. Javad Akhtari also assisted with the analysis of the data. Abolfazl Akbari prepared the manuscript, which Amir Seied Ali Mehbod and Mahdi Abastabar significantly revised. All authors read and approved the final manuscript.

Funding/Support: This paper was written using the data derived from a project financially supported by the AJA University of Medical Sciences, Tehran, Iran. The funding organization had no role in the design and conduct of the study, data collection and preparation of the manuscript.

\section{References}

1. Gmeiner M, Sonnberger M, Wurm G, Weis S. Glioblastoma with the appearance of arteriovenous malformation: pitfalls in diagnosis. Clin Neurol Neurosurg. 2013;115(5):501-6. doi: 10.1016/j.clineuro.2012.12.009. [PubMed: 23290419].

2. Shahideh M, Fallah A, Munoz DG, Loch Macdonald R. Systematic review of primary intracranial glioblastoma multiforme with symptomatic spinal metastases, with two illustrative patients. J Clin Neurosci. 2012;19(8):1080-6. doi: 10.1016/j.jocn.2011.09.024. [PubMed: 22704945].

3. Mohme M, Neidert MC, Regli L, Weller M, Martin R. Immunological challenges for peptide-based immunotherapy in glioblastoma. Cancer Treat Rev. 2014;40(2):248-58. doi: 10.1016/j.ctrv.2013.08.008. [PubMed: 24064197].

4. Vehlow A, Cordes N. Invasion as target for therapy of glioblastoma multiforme. Biochim Biophys Acta. 2013;1836(2):236-44. doi: 10.1016/j.bbcan.2013.07.001. [PubMed: 23891970].

5. Akbari A, Amanpour SMH, Muhammadnejad S, Ghahremani MH, Ghaffari SH, Dehpour AR, et al. Evaluation of antitumor activity of a TGF-beta receptor I inhibitor (SD-208) on human colon adenocarcinoma. Daru. 2014;22:47-53. doi: 10.1186/2008-2231-22-47. [PubMed: 24902843].

6. Mobini GR, Ghahremani MH, Amanpour S, Dehpour AR, Akbari A, Hoseiniharouni SM, Muhammadnejad S, Sheikhzade M, Abedkhojasteh $\mathrm{H}$, et al. ransforming growth factor beta-induced factor 2linked X(TGIF2LX) regulates two morphogenesis genes, Nir1 and Nir2 in human colorectal. Acta Medica Iranica. 2016;54(5):302-307. doi: $10.5402 / 2012 / 381428$
7. Sheikhzade M, Akbari A, Karkhaneh R, Ghassemi F, Sadeghi AR, Shahrzad Kavakani M, Mobini GR, Mohebbi M, Heidari M. Digoxin inhibits retinoblastoma through suppressing a non-canonical TGF $\beta$ signaling pathway. BJMMR. 2016;15(6):1-10.

8. Akbari A, Ghahremani MH, Mobini GR, et al. Down-regulation of miR$135 \mathrm{~b}$ in colon adenocarcinoma induced by a TGF- $\beta$ receptor I kinase inhibitor (SD-208). Iran J Basic Med Sci. 2015;18(9):856-861. doi: 10.1016/j.jmhi.2012.03.009.

9. Nauts HC, Fowler GA, Bogatko FH. A review of the influence of bacterial infection and of bacterial products (Coley's toxins) on malignant tumors in man; a critical analysis of 30 inoperable cases treated by Coley's mixed toxins, in which diagnosis was confirmed by microscopic examination selected for special study. Acta Med Scand Suppl. 1953;276:1-103. [PubMed: 13039964].

10. Akbari A, Mobini GR, Maghsoudi R, Akhtari J, Faghihloo E, Farahnejad Z. Modulation of transforming growth factor- $\beta$ signaling transducers in colon adenocarcinoma cells induced by staphylococcal enterotoxin B. Mol Med Rep. 2016;13(1):909-914. doi:10.3892/mmr.2015.4596. [PubMed: 26647993].

11. Zacharski LR, Sukhatme VP. Coley's toxin revisited: immunotherapy or plasminogen activator therapy of cancer?. J Thromb Haemost. 2005;3(3):424-7. doi: 10.1111/j.1538-7836.2005.01110.x. [PubMed: $15748226]$

12. Hoption Cann SA, van Netten JP, van Netten C. Dr William Coley and tumour regression: a place in history or in the future. Postgrad Med J. 2003;79(938):672-80. [PubMed:14707241].

13. Michl P, Buchholz M, Rolke M, Kunsch S, Löhr M, McClane B, et al. Claudin-4: a new target for pancreatic cancer treatment using Clostridium perfringens enterotoxin. Gastroenterology. 2001;121(3):678-84. [PubMed: 11522752].

14. Patyar S, Joshi R, Byrav DS, Prakash A, Medhi B, Das BK. Bacteria in cancer therapy: a novel experimental strategy. J Biomed Sci. 2010;17(1):21. doi: 10.1186/1423-0127-17-21. [PubMed: 20331869].

15. Kominsky SL, Vali M, Korz D, Gabig TG, Weitzman SA, Argani P, et al. Clostridium perfringens enterotoxin elicits rapid and specific cytolysis of breast carcinoma cells mediated through tight junction proteins claudin 3 and 4. Am J Path. 2004;164(5):1627-33.

16. Gao Z, McClane BA. Use of Clostridium perfringens enterotoxin and the enterotoxin receptor-binding domain (C-CPE) for cancer treatment: opportunities and challenges. J Toxicol. 2011;2012 doi: http://dx.doi.org/10.1155/2012/981626.

17. Ansiaux R, Gallez B. Use of botulinum toxins in cancer therapy. Expert Opin Investig Drugs. 2007;16(2):209-18. doi: 10.1517/13543784.16.2.209. [PubMed: 17243940].

18. Mahmoodzadeh Hosseini H, Ali Imani Fooladi A, Soleimanirad J, Reza Nourani M, Mahdavi M. Exosome/staphylococcal enterotoxin $\mathrm{B}$, an anti tumor compound against pancreatic cancer. $J$ BUON. 2014;19(2):440-8. [PubMed: 24965404].

19. Hui J, Xiao F, Li H, Cui X, Liu H, Hu F. Inhibiting tumor-cell growth by novel truncated staphylococcal enterotoxin C2 mutant. heng Wu Gong Cheng Xue Bao. 2011;27(6):891-9. [PubMed: 22034818].

20. Reis LO, Ferreira U, Billis A, Cagnon VH, Favaro WJ. Anti-angiogenic effects of the superantigen staphylococcal enterotoxin $B$ and bacillus Calmette-Guerin immunotherapy for nonmuscle invasive bladder cancer. J Urol. 2012;187(2):438-45. doi: 10.1016/j.juro.2011.10.022. [PubMed: 22177150].

21. Jung TY, Choi YD, Kim YH, Lee JJ, Kim HS, Kim JS, et al. Immunological characterization of glioblastoma cells for immunotherapy. Anticancer Res. 2013;33(6):2525-33. [PubMed: 23749904].

22. Fuller CL, Braciale VL. Selective induction of CD8+ cytotoxic T lymphocyte effector function by staphylococcus enterotoxin B.JImmunol. 1998;161(10):5179-86. [PubMed: 12435580].

23. Ascenzi P, Visca P, Ippolito G, Spallarossa A, Bolognesi M, Montecucco C. Anthrax toxin: a tripartite lethal combination. FEBS Lett. 2002;531(3):384-8. [PubMed: 12435580]. 
24. Engedal N, Skotland T, Torgersen ML, Sandvig K. Shiga toxin and its use in targeted cancer therapy and imaging. Microb Biotechnol. 2011;4(1):32-46. doi: 10.1111/j.1751-7915.2010.00180.x. [PubMed: 21255370].

25. Bandala C, Perez-Santos JL, Lara-Padilla E, Delgado Lopez G, Anaya-Ruiz M. Effect of botulinum toxin A on proliferation and apoptosis in the T47D breast cancer cell line. Asian Pac J Cancer Prev. 2013;14(2):891-4.
[PubMed: 23621257].

26. Brigotti M, Arfilli V, Carnicelli D, Rocchi L, Calcabrini C, Ricci F, et al. Shiga toxin 1, as DNA repair inhibitor, synergistically potentiates the activity of the anticancer drug, mafosfamide, on raji cells. Toxins (Basel). 2013;5(2):431-44. doi: 10.3390/toxins5020431. [PubMed: 23430607]. 